\title{
Rentabilidad Y Sostenibilidad Económica, Ambiental Y Social En Áreas Protegidas Aseguradas A Través Del Modelo De Gestión Estudio De Caso: Refugios Carrel Y Whymper Reserva Chimborazo
}

\author{
Carla Sofía Arguello Guadalupe \\ Luis Rafael Fiallos Ortega \\ María Flor Chinchuela \\ Paulina Beatriz Díaz Moyota \\ Catalina Margarita Verdugo Bernal \\ Carlos Arturo Jara Santillan
}

Docente - Investigador de la Facultad de Recursos Naturales

ESCUELA SUPERIOR POLITÉCNICA DE CHIMBORAZO - ECUADOR

\section{Miryan Isabel Quezada Piray}

Estudiante, Instituto de Postgrado y Educación Continua ESCUELA SUPERIOR POLITÉCNICA DE CHIMBORAZO - ECUADOR

doi: 10.19044/esj.2016.v13n2p77 URL:http://dx.doi.org/10.19044/esj.2016.v13n2p77

\begin{abstract}
This research is aimed to evaluate the management model for the operation of the shelters Carrel and Whymper within La Reserva de Produccion de Fauna Chimborazo (RPFCH - acronym in Spanish for this protected area) through the design and implementation of an evaluation matrix. This matrix tool is specifically designed to evaluate management models and operations of tourist services in protected areas. The model integrates three criteria that have to do with social, economic and environmental sustainability. The matrix has been designed based on four components: 1) The sustainability indicators created by the Economic Commission for Latin America and the Caribbean (CEPAL - acronym in Spanish), 2) A corporate social responsibility approach, 3) The global criteria of sustainable tourism and 4) A guide to good practices of sustainable tourism. These matrix components were adapted to the conditions of the tourist services offered at the Carrel and Whymper shelters. The evaluation detected that the current management model meets only $40 \%$ of the evaluation indicators sustainability criteria, which demonstrates a poor
\end{abstract}


sustainability model. Based on this review, a new management approach is suggested under the eco-efficient shelters model. This ensures that the investors not only reach economic profitability, but also they obtain longterm environmental and social sustainability. This model not only establishes parameters that allow for investors to make the appropriate economic and management decisions, but also establishes policies that ensure the conservation of protected areas.

Keywords: Environmental and social sustainability, profitability, management model, rpfch

\section{Resumen}

La presente investigación tuvo como objetivo evaluar el Modelo de Gestión para la Operación de los Refugios Carrel y Whymper de la Reserva de Producción Faunística Chimborazo (RPFCH); mediante el diseño y aplicación de una Matriz de Evaluación de Modelos de Gestión para la Operación de Servicios Turísticos en Áreas Protegidas, esta herramienta permitió integrar los tres criterios de sostenibilidad (social, económico y ambiental). La matriz fue diseñada en base a 4 elementos: 1) Categorías de Indicadores de Sostenibilidad de la Empresa creada por la Comisión Económica para América Latina y el Caribe (CEPAL), 2) Enfoque de Responsabilidad Social Corporativa, 3) Criterios Globales de Turismo Sostenibles y 4) Guía de Buenas Prácticas del Turismo Sostenible. Para su aplicación se realizó adaptaciones a las condiciones de los servicios turísticos que ofrecen los refugios Carrel y Whymper. La evaluación permitió detectar los criterios de sostenibilidad que no se cumplen en el modelo actual, mismo que obtuvo una valoración del $40 \%$ de cumplimiento sobre los indicadores evaluados, lo que evidencia una baja sostenibilidad del modelo. Por ello se plantea una nueva propuesta de Modelo de Gestión bajo el modelo de refugios ecoeficientes, asegurando que el inversionista no solo alcance una rentabilidad económica sino una sostenibilidad ambiental y social a largo plazo. Este modelo no solo establece parámetros que permitirán guiar al inversionista por el camino correcto, sino propone normativas que aseguraran la conservación del área protegida.

Palabras-claves: Rentabilidad económica, sostenibilidad ambiental y social, modelo de gestión, rpfch

\section{Introducción}

El Ecuador a través de su marco normativo establece: “el derecho de la naturaleza o Pacha Mama, a reproducirse y desarrollar la vida, tiene derecho a que se respete integralmente su existencia y el mantenimiento y 
regeneración de sus ciclos vitales, estructura, funciones al igual que sus procesos evolutivos” (ASAMBLEA CONSTITUYENTE, 2008: 52). La Constitución Política a más de reconocer los derechos de la naturaleza, garantiza la conservación de la biodiversidad y el mantenimiento de las funciones ecológicas a través del Sistema Nacional de Áreas Protegidas (SNAP). El Estado asignará los recursos económicos necesarios para la sostenibilidad financiera del sistema, y fomentará la participación de las comunidades, pueblos y nacionalidades que han habitado ancestralmente las áreas protegidas durante su administración y gestión. (Ministerio del Ambiente, 2016:3).

Consecuentemente el país apunta a un crecimiento del sector turístico, con índices de calidad, seguridad y servicio, acordes a la demanda internacional, sus políticas públicas fomentan el desarrollo de un turismo sostenible en áreas protegidas. El Ministerio de Ambiente (MAE) ente regulador de la gestión en áreas protegidas, hace frente a la problemática en torno al deterioro de la infraestructura existente, que no brinda en términos generales las condiciones mínimas para entregar un servicio de calidad a los visitantes. Por ello de acuerdo a la planificación Institucional se genera el programa denominado: Proyecto de Delimitación Física y Desarrollo del Turismo Sostenible en el Patrimonio de Áreas Naturales del Estado - PANE, entre sus propuestas operativas están la realización de trabajos de reparación o mantenimiento de la planta turística existente o de construcción de nueva infraestructura (SEMPLADES, 2013-2017: 3)

Es así que de la Reserva de Producción Faunística de Chimborazo, al ser considerada la quinta área protegida más visitada en el año 2015, con más de 145 especies endémicas de flora, con la mayor cantidad de mamíferos de la familia camelidae -vicuña, llama, alpaca del país, con 31 especies de aves, y la única área protegida del país donde se puede encontrar dos nevados contiguos, el Chimborazo con 6.310 m.s.n.m.,(el más alto del Ecuador); y, el Carihuayrazo con 5.020 m.s.n.m; entra al Proyecto y se remodelan los Refugios Carrel y Whymper (Ministerio del Ambiente, 2015: $10)$.

La Reserva de Producción Faunística Chimborazo fue creada en 1987 y cuenta con 58.560 ha protegidas, sus refugios fueron remodelados a partir del año 2011. De esta forma, el MAE identifica como prioritario poseer un modelo de gestión para la operación de los refugios y en diciembre 2013 a través del Proyecto de Sostenibilidad Financiera del SNAP, entrega el "Modelo de Gestión para la Operación de Servicios Turísticos en la Reserva de Producción de Fauna Chimborazo (RPFCH), Refugios de Alta Montaña "Primos Carrel” y "Edward Whymper, mismo que fue construido en función del diagnóstico situacional de la Reserva en el año 2013 (Arias, 2013:8) 
En enero del 2015 concluye la remodelación de los refugios y en marzo del mismo año, el MAE concesiona su uso a la empresa privada entregando al empresario el modelo de gestión de los refugios elaborado en el año 2013, el cual evidencia un análisis financiero poco atractivo para el inversionista, lo que, lo desmotiva y cae el proceso de concesión. Nuevamente se inicia éste proceso y en agosto de 2015, se suscribe un convenio con la Compañía "Andean Adventures Tour Operator \& Travel Agency Landvertours Cía. Ltda”, para la operación de los refugios (Piray, 2016: 29).

Una vez iniciada la operación turística de los Refugios, se evidencia la falta de una herramienta de gestión para la operación de los mismo. El actual "Modelo de Gestión para la Operación de Servicios Turísticos en la Reserva de Producción de Fauna Chimborazo (RPFCH), Refugios de Alta Montaña "Primos Carrel” y "Edward Whymper, resulta desactualizado y surge la necesidad de evaluarlo con el fin de establecer su pertinencia en las actuales condiciones y con la nueva infraestructura, junto a ello se busca medir la observancia de los objetivos nacionales de conservación y el cumplimiento de los programas de Uso Público y Turismo aprobados en la planificación anual del MAE (Ministerio del Ambiente -PGOA, 2015: 2)

Para evaluar el Modelo 2013, se trabajó bajo los criterios de Sostenibilidad de la Empresa, Responsabilidad Social Corporativa, Criterios Globales de Turismo Sostenibles y Buenas Prácticas del Turismo Sostenible, para ello se construyó una matriz, misma que incluye indicadores de sostenibilidad aprobados a nivel internacional, y que han sido validados en el Ecuador por Instituciones como: Rainforest Alliance. Con la construcción y posterior evaluación de la misma se puede identificar los indicadores que debería ser evaluados en un área protegida que cumple con parámetros de sostenibilidad (Piray, 2016: 66).

Las empresas catalogadas como empresas sostenibles tiene 3 beneficios: 1) Sociales pues la gestión sostenible de las empresas está ligada con su entorno local, y debe contribuir con el desarrollo de las comunidades en donde realizan su operación.

2) Beneficios ambientales ya que se evidencia la disminución del consumo de recursos, se disminuye los desechos y las emisiones contaminantes, lo cual reduce el impacto sobre el medio ambiente y;

3) Beneficios económicos pues la gestión sostenible de una empresa es la interacción balanceada entre el uso apropiado de los recursos naturales , culturales, el mejoramiento de la calidad de vida de las comunidades locales y la viabilidad económica que, además, favorece el desarrollo nacional (Rainforest Alliance, 2009: 11-13).

Los Criterios Globales de Turismo Sostenibles resaltan la importancia de maximizar los beneficios sociales, disminuir los impactos 
ambientales y en general demostrar una gestión sostenible eficaz. Estos criterios promueven una mejor comprensión de las prácticas de turismo sostenible y la adopción de sus principios universales, estableciendo los principios mínimos de sostenibilidad que una empresa turística debe desear, para proteger y conservar los recursos naturales y culturales de la zona de influencia, al tiempo que aseguran que el turismo cumpla con su potencial como herramienta para aliviar la pobreza (Alianza GSTC, 2012:3-7).

Las Buenas Prácticas del Turismo Sostenible son una herramienta creada con el propósito de minimizar los impactos negativos y maximizar los beneficios de la actividad turística en el entorno sociocultural, ambiental y empresarial. Con ello el empresario turístico responsable podrá contar con una guía para realizar una gestión sostenible de los recursos de su empresa de una manera sencilla y efectiva (Rainforest Alliance, 2008: 13)

Con estas herramientas se realiza la evaluación del modelo de gestión elaborado en el año 2013 y se determina el nivel de sostenibilidad del mismo para la Reserva, obteniendo resultados que permiten concluir que solo se cumple un $40 \%$ de los indicadores evaluados, lo que hace suponer que el modelo evidencia un nivel de sostenibilidad bajo. Lo que claramente es divergente con los objetivos de sostenibilidad establecidos en el Plan Estratégico del Sistema Nacional de Áreas Protegidas del Ecuador (Ministerio del Ambiente, 2007-1016:20-25)

Por ello se plantea una propuesta de un nuevo Modelo de Gestión, misma que tiene por objetivo asegurar que los Refugios de alta montaña Carrel y Whymper operen bajo el modelo de empresas eco-eficientes sujetos a la aplicación de Buenas Prácticas para el Turismo Sostenible con un enfoque en los Criterios Globales de Turismo Sostenible y el de Responsabilidad Social Corporativa o Responsabilidad Social Empresarial (RSE), esto a su vez motiva tanto al inversionista como al MAE a lograr ventajas competitivas a través de la ecoeficiencia, generando menor impacto ambiental, asegurando un desarrollo integral de los recursos humanos y de la comunidad local. Gracias a un trabajo conjunto la sostenibilidad en los ámbitos social, económico y ambiental a largo plazo de la Reserva de Producción Faunística Chimborazo está certificada (MINAM, 2009: 9)

\section{Metodología}

La presente investigación es de tipo no experimental descriptiva, se aplicó el método de investigación deductivo pues desde las condiciones generales de sostenibilidad se derriba las condiciones particulares de la Reserva. El método parte de verdades previamente establecidas como principios generales, para luego aplicarlo a casos individuales y comprobar así su validez, a través de la investigación bibliográfica y de la observación 
de campo. Además se utilizó el método inductivo, la inducción va de lo particular a lo general, lo que permite emplear métodos de la observación, análisis de hechos y fenómenos particulares, que posteriormente serán descritos en la investigación

Para el cumplimiento de cada uno de los objetivos planteados se empleó la siguiente metodología:

\section{Análisis del modelo de gestión existente}

Para su cumplimiento se efectuó lo siguiente:

Se revisó y analizó la información secundaria del documento Modelo de Gestión para la Operación de Servicios Turísticos en la Reserva de Producción de Fauna de Chimborazo (RPFCH), Caso Refugios Carrel y Whymper, para posteriormente sistematizar e interpretar la información existente y plantear conclusiones al respecto.

\section{Desarrollo de una matriz de evaluación con enfoque de sostenibilidad en los ámbitos social, económico y ambiental.}

Para el cumplimiento de este objetivo se procedió a levantar información primaria mediante observación in situ en la zona de estudio, al mismo tiempo se analizó los componentes para construir la matriz de evaluación (Indicadores de Sostenibilidad de la empresa con enfoque de Responsabilidad Social Corporativa o Responsabilidad Social Empresarial (CEPAL) y de Buenas Prácticas para el Turismo Sostenible, enfocada en los Criterios Globales de Turismo Sostenible.

Con ello, en el programa Excel se elaboró la matriz que recoge todos los indicadores de sostenibilidad social, económico y ambiental, que se aplican a la realidad de la RPFCH. La matriz de evaluación se convierte en una herramienta que genera una línea base para posteriores evaluaciones y además que permite realizar un monitoreo del avance en la administración y gestión de los indicadores sociales, económicos y ambientales. Pues con ello se podrán detectar a tiempo problemas que deberán ser corregidos con medidas cautelares.

Con la matriz se procede a evaluar el cumplimiento o no de cada indicador en el modelo actual, con la calificación de 0 (cero) no se cumple y 1 (uno) se cumple. Se suma el total de indicadores que cumplen el modelo, se obtiene el porcentaje total de los tres ámbitos y se determina el nivel de sostenibilidad de acuerdo a lo planteado en el cuadro 1. 
Cuadro 1: Niveles de sostenibilidad

\begin{tabular}{|c|c|}
\hline Niveles de Sostenibilidad & Descripción \\
\hline Alta Sostenibilidad & $\begin{array}{l}\text { El modelo de gestión planteado cumple con el } 100 \% \text { de los } \\
\text { indicadores de sostenibilidad (social, económico y ambiental) }\end{array}$ \\
\hline Media Sostenibilidad & $\begin{array}{c}\text { El modelo de gestión planteado está dentro del rango de } \\
\text { cumplimiento del 50\% al 99\% de los indicadores de } \\
\text { sostenibilidad (social, económico y ambiental) }\end{array}$ \\
\hline Baja Sostenibilidad & $\begin{array}{l}\text { El modelo de gestión planteado está dentro del rango de } \\
\text { cumplimiento del 30\% al } 49 \% \text { de los indicadores de } \\
\text { sostenibilidad (social, económico y ambiental), por lo tanto es } \\
\text { poco coherente con los tres criterios de sostenibilidad }\end{array}$ \\
\hline No Sostenible & $\begin{array}{l}\text { El modelo de gestión planteado está dentro del rango de } \\
\text { cumplimiento entre } 0 \text { y } 29 \% \text { de los indicadores de } \\
\text { sostenibilidad (social, económico y ambiental), por lo tanto el } \\
\text { modelo de gestión planteado no integra en su contenido } \\
\text { ninguno de los tres criterios de sostenibilidad }\end{array}$ \\
\hline
\end{tabular}

Realizado por: Myrian Isabel Piray Quezada

Elaboración de una propuesta para mejorar el modelo de gestión existente de los Refugios Carrel y Whymper.

Para plantear la nueva propuesta una vez identificados los nudos críticos y con un enfoque de sostenibilidad se utilizó elementos como:

$>\quad$ Buenas Practicas para el Turismo Sostenible

$>\quad$ La Ecoeficiencia

$>\quad$ Responsabilidad Social Empresarial (RSE)

Para la actualización de información se trabajó con el Sistema de información Geográfica (SIG), que permitió a través del análisis espacial con ortofotos y georeferenciación innovar la oferta existente acorde a las características de los atractivos, servicios e infraestructura. Estas rutas se proponen como una nueva oferta de servicio de los refugios de Alta montaña Carrel y Whymper. Además se identificó atractivos complementarios, planta turística, infraestructura y superestructura turística.

Para medir la Rentabilidad de la empresa sostenible se aplicaron indicadores de rentabilidad financiera como: VAN, TIR, Relación Costo/Beneficio y Punto de equilibrio.

\section{Resultados}

\section{Análisis del modelo de gestión existente}

El "Modelo de Gestión para la Operación de Servicios Turísticos en la Reserva de Producción Faunística Chimborazo (RPFCH), Refugios de Alta Montaña "Primos Carrel” y Edward Whymper" elaborado en el año 2013, fue el único documento existente para la administración y operación de los refugios de Chimborazo hasta la fecha de elaboración del estudio, el cual cuenta con la siguiente estructura: 


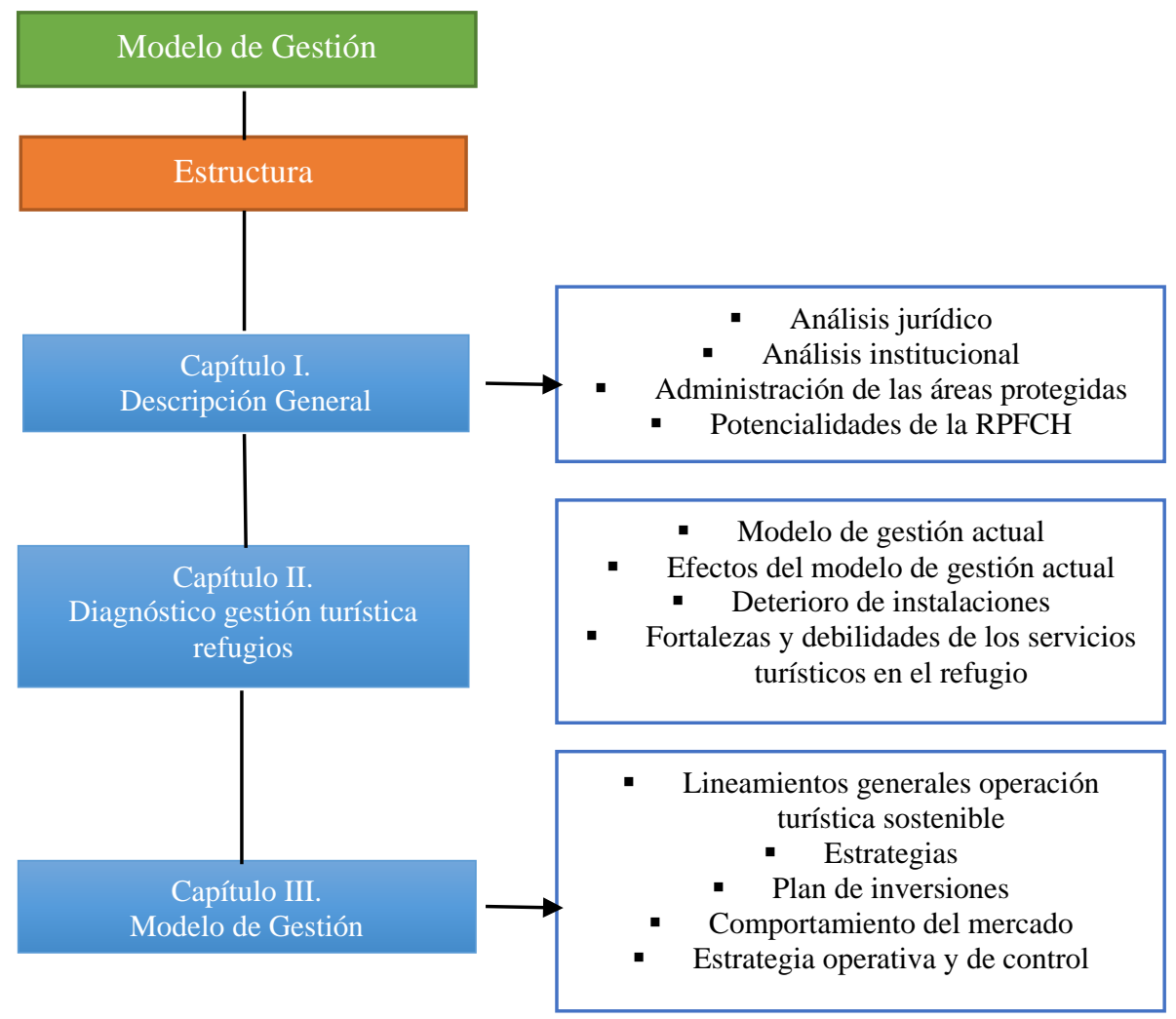

Figura 1. Estructura del Modelo de Gestión 2013

Realizado por: Myrian Isabel Piray Quezada

El análisis se realizó en función de los ámbitos en la siguiente secuencia: Ámbito social, ámbito económico, ámbito ambiental.

\section{Ámbito Social}

El modelo de gestión presenta información del rol del MAE como autoridad ambiental y de la RPFCH. Expone sobre la administración histórica de los refugios desde 1979, iniciando su administración a cargo del Ministerio de Turismo hasta agosto del 2011, cuando este Ministerio transfiere a título gratuito la posesión, uso, goce y administración de las infraestructuras y mobiliario de los refugios a favor del MAE.

Posteriormente se presenta un nutrido compendio jurídico de carácter ambiental y turístico, partiendo desde la Constitución Política del estado de Ecuador, leyes, reglamentos, acuerdos, normas, planes a nivel nacional y territorial; muchos de ellos no se encuentra vigentes y han sido derogados; e incluyo hay normas que no son aplicables en áreas protegidas. Por lo tanto, se identifica poca claridad y falta articulación de éstas normativas con la realidad del área protegida. 
El modelo de gestión elaborado, se basa en el Plan de Manejo de la RPFCH de 1992 y el Plan Gerencial, herramientas de planificación no aplicadas en la actualidad en el área. Los programas de manejo actuales son diferentes a los que se presentan en el documento, el área protegida trabaja desde el 2014 con el Plan Gerencial Operativo Anual "PGOA" con cinco programas a saber: Control y Vigilancia, Manejo de la Biodiversidad (Sub programa: Investigación y Monitoreo), Comunicación, Educación y Participación Ambiental, Uso Público y Turismo y Administración y Planificación. (Ministerio del Ambiente -PGOA, 2015: 2)

En lo que respecta a la participación comunitaria en la zona de influencia de la RPFCH el modelo identifica solo 13 comunidades, cuando dentro de la Reserva están 11 y articuladas al área protegida están 41 comunidades. Como parte del involucramiento de la comunidad se plantea que al menos el $80 \%$ del personal de los refugios sean habitantes de las comunidades locales, lo que asegura la generación de empleo en la localidad, sin embargo, no se considera la política del MAE que prioriza la oferta de servicios turísticos de calidad en las áreas protegidas, lo cual sería difícil de cumplir debido al bajo nivel educativo de las comunidades de la zona.

Si bien es cierto la gestión del recurso humano presenta un detalle del personal necesario para la operación de los refugios, que incluye presupuestos referenciales, para cubrir remuneración y obligaciones mínimas contractuales, no se toma en cuenta las nuevas reformas a las políticas laborales, además es importante considerar que el personal de la Reserva trabaja los 365 días del año en los dos refugios.

La estrategia de comunicación establece los lineamientos entre la oficina central, la Dirección Provincial de Ambiente Chimborazo, la Administración de la reserva, administración de los refugios, y actores locales, pero también evidencia el conflicto de intereses por la administración de los refugios, concluyendo que existe una carencia de información necesaria para una efectiva operación de los mismos.

\section{Ámbito Económico}

En el ámbito económico hace referencia a la potencialidad del centro de visitantes "El Arenal” y de los refugios Carrel y Whymper, servicios que para el año 2013 no estaban remodelados lo cual demuestra un análisis desactualizado. Además el modelo de gestión hace referencia a un estudio de mercado, elaborado en base a información del 2011 y 2012 con proyecciones al 2014, el cual no refleja la realidad de la afluencia turística al área.

El análisis FODA fue desarrollado en base a una realidad distinta a la actual por lo cual no proporciona valor a la admiración de los refugios. Para ello se recomienda realizar un nuevo análisis de las condiciones de los 
refugios y determinar las condiciones positivas o negativas que influyan en la prestación de los servicios turísticos.

El modelo de gestión propone una tarifa de hospedaje en los refugios que será de USD 12,50 sin impuestos, tarifa acorde al objetivo social de la época. Actualmente esa tarifa debe ser analizada ya que pese a mostrar un flujo de ingresos que permitía cubrir los costos y gastos operativos, no asegura la sostenibilidad económica, evidenciándose una corrida financiera con una recuperación del capital a largo plazo, en el octavo año de operación, situación poco atractiva para el inversionista privado.

El modelo muestra una redistribución de los beneficios de los refugios al área protegida a través de la asignación de responsabilidades y obligaciones al administrador de los refugios, lo que evitaría que el Estado asuma costos de mantenimiento y operación de los mismos. Sin embargo, no muestra que mecanismo legal se podría aplicar para cumplir con este propósito.

\section{Ámbito Ambiental}

En el ámbito ambiental se propone el uso potencial de las actividades de Manejo de Fauna Silvestre, Conservación y Turismo, de acuerdo a lo expuesto en el Sistema de Manejo de Visitantes (SIMAVIS), esta herramienta de gestión no se aplica actualmente en la reserva. El Manual Operativo hace referencia a la gestión ambiental con lineamientos básicos para reducción y manejo de desechos resultante de la operación de los refugios. Sin duda esto resulta muy elemental considerando que el aspecto ambiental es fundamental en un área protegida.

A continuación se resumen los principales errores del modelo:

Cuadro 2. Errores del modelo de gestión en los ámbitos de sostenibilidad

\begin{tabular}{|c|c|c|}
\hline Ámbito Social & Ámbito Económico & Ámbito Ambiental \\
\hline $\begin{array}{l}\text { - No existe una política de } \\
\text { sostenibilidad para la } \\
\text { administración de los } \\
\text { refugios en los ámbitos } \\
\text { social, económico y } \\
\text { ambiental. }\end{array}$ & $\begin{array}{l}\text { - La sostenibilidad } \\
\text { económica que maneja el } \\
\text { modelo de gestión, no es } \\
\text { atractiva a la inversión } \\
\text { privada ya que evidencia } \\
\text { indicadores de rentabilidad } \\
\text { con una recuperación del } \\
\text { capital a largo plazo. }\end{array}$ & $\begin{array}{l}\text { - El modelo no profundiza } \\
\text { sobre la gestión ambiental, } \\
\text { dejando de lado el aporte a } \\
\text { la conservación de la } \\
\text { biodiversidad y } \\
\text { conservación del área } \\
\text { protegida. }\end{array}$ \\
\hline $\begin{array}{l}\text { - La gestión de los recursos } \\
\text { humanos es importante para } \\
\text { la sostenibilidad, sin } \\
\text { embargo el modelo no hace } \\
\text { énfasis en este tema. }\end{array}$ & $\begin{array}{l}\text { - El modelo habla sobre la } \\
\text { redistribución de los } \\
\text { beneficios de los refugios al } \\
\text { área protegida, pero no } \\
\text { muestra que mecanismo } \\
\text { legal se aplicarán para } \\
\text { cumplir con este propósito. }\end{array}$ & \\
\hline $\begin{array}{l}\text { - La participación } \\
\text { comunitaria carece de los }\end{array}$ & $\begin{array}{l}\text { - El producto de los refugios } \\
\text { no se basa en una oferta }\end{array}$ & \\
\hline
\end{tabular}




\begin{tabular}{|c|c|c|}
\hline Ámbito Social & Ámbito Económico & Ámbito Ambiental \\
\hline $\begin{array}{c}\text { mecanismos para su } \\
\text { involucramiento en el } \\
\text { modelo. }\end{array}$ & $\begin{array}{c}\text { atractiva que motive a los } \\
\text { visitantes. }\end{array}$ \\
\hline $\begin{array}{c}\text { - El modelo no presenta las } \\
\text { herramientas para medir el } \\
\text { nivel de satisfacción del } \\
\text { visitante. }\end{array}$ & $\begin{array}{c}\text { - El estudio de mercado, fue } \\
\text { elaborado en base a } \\
\text { proyecciones mostrando un } \\
\text { escenario poco real de la } \\
\text { demanda de servicios } \\
\text { turísticos en la Reserva. }\end{array}$ \\
\hline
\end{tabular}

Realizado por: Myrian Isabel Piray Quezada

$>$ Desarrollar una matriz de evaluación con enfoque de sostenibilidad en los ámbitos social, económico y ambiental.

La Evaluación de modelo de gestión bajo los criterios de sostenibilidad (social, económico y ambiental) parte del análisis de dos herramientas de gestión de sostenibilidad:

1. Categorías de Indicadores de Sostenibilidad de la Empresa con el enfoque de Responsabilidad Social Corporativa o Responsabilidad Social Empresarial (RSE). (CEPAL. Nuñez, 2006, p.65) y,

2. Manual de Buenas Prácticas para el Turismo Sostenible (Rainforest Alliance, 2008), con enfoque en los Criterios Globales de Turismo Sostenible.

Análisis de las Categorías de Indicadores de Sostenibilidad de la empresa con el enfoque de Responsabilidad Social Corporativa o Responsabilidad Social Empresarial (RSE).

El análisis de esta herramienta de sostenibilidad, se realizó partiendo de la conceptualización de Responsabilidad Social Empresarial RSE y ecoeficiencia.

La Responsabilidad Social Empresarial RSE nace del ámbito privado bajo la siguiente reflexión: el desarrollo de la actividad económica de la empresa tiene como objetivo generar beneficios para sus propietarios o accionistas con impactos importantes en lo ambiental y social, frente a lo cual la empresa debe cumplir su responsabilidad para solventar los problemas. En este sentido la empresa ya no solo busca maximizar sus utilidades sino que debe convertir los aspectos ambientales y sociales en un activo intangible de la misma, permitiéndole introducirse en el desarrollo sostenible. Consecuentemente la empresa debe actuar bajo un enfoque integrado de estos tres aspectos en el desarrollo de su gestión.

Ligado estrechamente a las iniciativas de RSE y al desarrollo sostenible existe un enfoque de política ambiental para el sector empresarial que es la ecoeficiencia, proceso definido como "Proporcionar bienes y servicios a un precio competitivo, que satisfaga las necesidades humanas y la 
calidad de vida, al tiempo que reduzca progresivamente el impacto ambiental y la intensidad de la utilización de recursos a lo largo del ciclo de vida, hasta un nivel compatible con la capacidad de carga estimada del planeta" (WBCSD, 1996:1).

Fundamentado en los enfoques de RSE y ecoeficiencia la Comisión Económica para América Latina y el Caribe “CEPAL”, en el 2006 elabora las Categorías de indicadores de Sostenibilidad de la Empresa, en función de aspectos ambientales, sociales y económicos.

\section{Indicadores ambientales}

Los aspectos críticos que deben evaluar los indicadores ambientales tienen que ver con los impactos de la actividad de la organización en la utilización de los recursos y en la generación de residuos/ contaminación, así como en los efectos en la salud de las personas y los ecosistemas.

\section{Indicadores sociales}

Los indicadores sociales de la sostenibilidad en la empresa u organización incluyen los referidos al ámbito interno de la organización y los del ámbito externo.

\section{Indicadores económicos}

Además de información financiera-contable, en gran medida orientada a evaluar la rentabilidad del capital, los indicadores económicos de sostenibilidad deben evaluar la productividad del trabajo, salarios y beneficios, inversiones en investigación, desarrollo e innovación, impuestos o contribución total a las arcas de la administración pública y relaciones económicas con proveedores. Estos se resumen en el cuadro3.

Cuadro. 3. Categorías de indicadores de Sostenibilidad de la Empresa

\begin{tabular}{|c} 
Cuadro. 3. Categorías de indicadores de Sostenibilidad de la Empresa \\
Indicadores ambientales \\
Energía \\
Materiales \\
Agua \\
Emisiones, efluentes y residuos \\
Transporte \\
Proveedores \\
Productos y servicios \\
Utilización del suelo y biodiversidad \\
Cumplimiento de la ley \\
Indicadores sociales \\
Seguridad e higiene en el trabajo \\
Políticas de no discriminación en función del género, etnia, edad \\
Políticas de inserción de colectivos desfavorecidos \\
Formación del personal de la empresa \\
Grado de satisfacción en el trabajo de los empleados \\
Permanencia de los empleados en la empresa
\end{tabular}


Información y participación de los trabajadores en la marcha de la entidad

\section{Indicadores económicos}

Productividad del trabajo

Salarios y beneficios

Inversiones en investigación, desarrollo e innovación

Impuestos o contribución total a las arcas de la administración pública

Relaciones económicas con proveedores

Fuente: DDSAH, CEPAL, 2006

Realizado por: Myriam Piray Quezada

\section{Manual de Buenas Prácticas para el Turismo Sostenible, con enfoque en los Criterios Globales de Turismo Sostenible}

La segunda herramienta de sostenibilidad permite a los empresarios turísticos adoptar prácticas de gestión sostenibles para cumplir con los Criterios Globales de Turismo Sostenible orientados en hoteles y operadores de turismo.

La Alianza para los Criterios Mundiales de Turismo Sostenible (Alianza GSTC, por sus siglas en inglés) presentó los Criterios Mundiales de Turismo Sostenible en el Congreso Mundial de la Naturaleza, en octubre de 2008. Estos criterios promueven una mejor comprensión de las prácticas de turismo sostenible y la adopción de sus principios universales, estableciendo los principios mínimos de sostenibilidad a los que una empresa turística debe aspirar, para proteger y conservar los recursos naturales y culturales del mundo, al tiempo que aseguran que el turismo cumpla con su potencial para aliviar la pobreza.

Según Alianza Global 2008, los Criterios de Turismo Sostenible son parte de la respuesta brindada por la comunidad turística frente a los desafíos mundiales que se presentan en los Objetivos de Desarrollo del Milenio de las Naciones Unidas. La mitigación de la pobreza y la sostenibilidad ambiental. Temas transversales como el cambio climático se incluyen en estos criterios.

Los criterios se organizan alrededor de los temas principales como: la planificación eficaz para la sostenibilidad; la maximización de los beneficios sociales y económicos para la comunidad local; el mejoramiento del patrimonio cultural; y la reducción de los impactos negativos sobre el ambiente. En función a éstos temas se desprenden una serie de indicadores que guían una gestión sostenible de las empresas. Por otro lado las buenas prácticas están encaminadas a la gestión empresarial, y plantean una serie de recomendaciones y acciones que conducen a los tres ejes de la sostenibilidad: económico, sociocultural y ambiental, que deben estar relacionados de forma equitativa, ya que si uno de estos ejes falta o no se cumple con los criterios de sostenibilidad.

El eje económico estipula que la actividad se desarrolle a base de prácticas empresariales que logren el crecimiento y la sostenibilidad 
económica en el largo plazo, beneficiando a los propietarios, empleados y a las comunidades locales. En lo ambiental la actividad debe desarrollarse considerando, la forma en que se utiliza los recursos naturales y las acciones de aporte a la conservación. Y el eje socio-cultural plantea una actividad que se realiza respetando la cultura y contribuyendo a la revitalización cultural, sin afectar a la comunidad o comunidades locales. De este análisis se determina la matriz de evaluación.

\section{Evaluación del modelo de gestión de los refugios con enfoque de Sostenibilidad}

Al ser un modelo de gestión que será aplicado en un área protegida es pertinente analizar el cumplimiento de los objetivos del área, de los programas de Uso Público y Turismo a través del Plan de Manejo de Visitantes como una herramienta de planificación y gestión del territorio que permite el manejo organizado de los visitantes en relación a los sitios de visita, con el objetivo de satisfacer las expectativas del visitante sin que cause impactos ambientales sobre los recursos naturales del área protegida. (Ministerio de Ambiente, 2015: 4). Conservación de ecosistemas, manejo sustentable de la vida silvestre, la educación ambiental, la restauración de ecosistemas y el turismo orientado a la naturaleza entre otros.

La matriz de evaluación cuenta con 10 indicadores para el ámbito social, 7 indicadores para el ámbito económico y 12 indicadores para el ámbito ambiental. La matriz se muestra a continuación.

Cuadro 4. Matriz de evaluación

\begin{tabular}{|c|c|c|c|c|}
\hline \multirow{2}{*}{$\begin{array}{l}\text { Ámbitos } \\
\text { de } \\
\text { Sostenibili } \\
\text { dad }\end{array}$} & \multirow[t]{2}{*}{ Indicadores } & \multirow[b]{2}{*}{ Descriptor } & \multicolumn{2}{|c|}{ Ponderaciones } \\
\hline & & & Cumple & $\begin{array}{c}\text { No } \\
\text { cumple }\end{array}$ \\
\hline \multirow{8}{*}{$\begin{array}{l}\text { Ámbito } \\
\text { Social }\end{array}$} & Ambiente interno & & & \\
\hline & Gestión de Sostenibilidad & & & \\
\hline & $\begin{array}{l}\text { AS1. Declaración de una } \\
\text { política de sostenibilidad }\end{array}$ & $\begin{array}{l}\text { La política incluye aspectos } \\
\text { ambientales, sociales y económicos } \\
\text { para la gestión de la empresa }\end{array}$ & & 0 \\
\hline & $\begin{array}{l}\text { AS2. Existen políticas } \\
\text { empresariales }\end{array}$ & $\begin{array}{l}\text { La empresa tiene como mínimo: } \\
\text { política de servicio, política } \\
\text { ambiental, política social, política de } \\
\text { gestión humana, política de } \\
\text { seguridad. }\end{array}$ & & 0 \\
\hline & $\begin{array}{l}\text { AS3. Aplicación en la gestión } \\
\text { de la calidad }\end{array}$ & $\begin{array}{l}\text { Determinar directrices que la } \\
\text { empresa debe tomar para garantizar } \\
\text { la calidad de los productos y } \\
\text { servicios }\end{array}$ & & 0 \\
\hline & $\begin{array}{c}\text { AS4. Establece formas } \\
\text { monitoreo y acciones } \\
\text { correctivas }\end{array}$ & $\begin{array}{l}\text { Orienta acciones para monitoreo de } \\
\text { impactos ambientales y sociales } \\
\text { producidos por la empresa }\end{array}$ & & 0 \\
\hline & Gestión de Recursos Humanos & & & \\
\hline & AS5. Establece directrices para & Establecimiento de directrices para & & 0 \\
\hline
\end{tabular}




\begin{tabular}{|c|c|c|c|c|}
\hline \multirow{2}{*}{$\begin{array}{l}\text { Ámbitos } \\
\text { de } \\
\text { Sostenibili } \\
\text { dad }\end{array}$} & \multirow[t]{2}{*}{ Indicadores } & \multirow[b]{2}{*}{ Descriptor } & \multicolumn{2}{|c|}{ Ponderaciones } \\
\hline & & & Cumple & $\begin{array}{c}\text { No } \\
\text { cumple }\end{array}$ \\
\hline & $\begin{array}{l}\text { la salud y seguridad en el } \\
\text { trabajo }\end{array}$ & $\begin{array}{l}\text { brindar un servicio seguro en todas } \\
\text { las acciones y servicios ofertados, } \\
\text { bajo los conceptos de sostenibilidad. }\end{array}$ & & \\
\hline & $\begin{array}{l}\text { AS6. Contempla la formación } \\
\text { del personal de la empresa }\end{array}$ & $\begin{array}{l}\text { Evidencia la capacitación periódica } \\
\text { para mejorar el desempeño de las } \\
\text { competencias laborales }\end{array}$ & & 0 \\
\hline & $\begin{array}{l}\text { AS7. Define el grado de } \\
\text { satisfacción en el trabajo de los } \\
\text { empleados }\end{array}$ & $\begin{array}{l}\text { Muestra los mecanismos para medir } \\
\text { el grado de satisfacción de los } \\
\text { empleados }\end{array}$ & & 0 \\
\hline & $\begin{array}{l}\text { AS8. Permanencia de los } \\
\text { empleados en la empresa }\end{array}$ & $\begin{array}{l}\text { Establece lineamientos útiles para } \\
\text { brindar estabilidad laboral en la } \\
\text { empresa }\end{array}$ & & 0 \\
\hline & Ambiente externo & & & \\
\hline & $\begin{array}{c}\text { AS9. La empresa turística } \\
\text { contribuye al desarrollo local } \\
\text { de la comunidad }\end{array}$ & $\begin{array}{l}\text { Lineamientos para la contratación de } \\
\text { personal local }\end{array}$ & 1 & \\
\hline & $\begin{array}{l}\text { AS10. La operación turística } \\
\text { aporta al rescate, respeto y } \\
\text { protección de las culturas y } \\
\text { poblaciones locales } \\
\end{array}$ & $\begin{array}{l}\text { Definir una política que fomente el } \\
\text { respeto y contribución a la cultura } \\
\text { local }\end{array}$ & & 0 \\
\hline & $\begin{array}{c}\text { AS 11. La empresa mide el } \\
\text { nivel de satisfacción de los } \\
\text { visitantes }\end{array}$ & $\begin{array}{l}\text { La empresa establece instrumentos } \\
\text { que midan la satisfacción del } \\
\text { visitante }\end{array}$ & 1 & \\
\hline & Subtotal 1 Ámbito Social & & 2 & \\
\hline \multirow{8}{*}{$\begin{array}{l}\text { Ámbito } \\
\text { Económic } \\
\quad \text { o }\end{array}$} & $\begin{array}{l}\text { AE1. Refleja productividad de } \\
\text { la empresa }\end{array}$ & $\begin{array}{l}\text { Muestra una oferta amplia y } \\
\text { atractiva para el visitante }\end{array}$ & & 0 \\
\hline & $\begin{array}{l}\text { AE2. Demuestra rentabilidad } \\
\text { de la empresa }\end{array}$ & $\begin{array}{l}\text { Establece un control y seguimiento } \\
\text { de los procesos financieros }\end{array}$ & & 0 \\
\hline & $\begin{array}{l}\text { AE3. Determina salarios y } \\
\text { beneficios }\end{array}$ & $\begin{array}{l}\text { Establece beneficios salariales } \\
\text { superiores al básico que dictamina la } \\
\text { ley laboral }\end{array}$ & & 0 \\
\hline & $\begin{array}{c}\text { AE4. Presenta inversiones en } \\
\text { investigación, desarrollo e } \\
\text { innovación }\end{array}$ & $\begin{array}{l}\text { Potencializa trabajos de } \\
\text { investigación }\end{array}$ & & 0 \\
\hline & $\begin{array}{l}\text { AE5. Refleja los impuestos o } \\
\text { contribución total a las arcas de } \\
\text { la administración pública }\end{array}$ & $\begin{array}{l}\text { Establece los impuestos a ser } \\
\text { tributados de acuerdo a la ley }\end{array}$ & 1 & \\
\hline & $\begin{array}{l}\text { AE6. Cumplimiento de } \\
\text { compromisos económicos con } \\
\text { proveedores }\end{array}$ & $\begin{array}{l}\text { Orientación de presupuesto para } \\
\text { cumplir con los proveedores }\end{array}$ & & 0 \\
\hline & $\begin{array}{l}\text { AE7. Lineamientos de gestión } \\
\text { de mercadeo }\end{array}$ & $\begin{array}{c}\text { Información sobre la oferta y } \\
\text { demanda para establecer mercados } \\
\text { potenciales }\end{array}$ & 1 & \\
\hline & Subtotal 2 Ámbito Económico & & 2 & \\
\hline \multirow{3}{*}{$\begin{array}{c}\text { Ámbito } \\
\text { Ambiental }\end{array}$} & AA1. Gestión del recurso agua & $\begin{array}{l}\text { Buenas prácticas de manejo para } \\
\text { reducir el consumo de agua }\end{array}$ & 1 & \\
\hline & $\begin{array}{l}\text { AA2. Uso de tecnología de } \\
\text { energía renovable }\end{array}$ & $\begin{array}{c}\text { Utilización de tecnologías } \\
\text { alternativas respetuosas con el } \\
\text { ambiente }\end{array}$ & 1 & \\
\hline & AA3. Minimizar el & Incluye medidas para reducir la & & 0 \\
\hline
\end{tabular}




\begin{tabular}{|c|c|c|c|c|}
\hline \multirow{2}{*}{$\begin{array}{l}\text { Ámbitos } \\
\text { de } \\
\text { Sostenibili } \\
\text { dad }\end{array}$} & \multirow[t]{2}{*}{ Indicadores } & \multirow[b]{2}{*}{ Descriptor } & \multicolumn{2}{|c|}{ Ponderaciones } \\
\hline & & & Cumple & $\begin{array}{l}\text { No } \\
\text { cumple }\end{array}$ \\
\hline & calentamiento global & $\begin{array}{c}\text { producción de gases de efecto } \\
\text { invernadero }\end{array}$ & & \\
\hline & $\begin{array}{l}\text { AA4. Aporte a la conservación } \\
\text { de la biodiversidad }\end{array}$ & $\begin{array}{l}\text { Estrategias para minimizar el daño } \\
\text { sobre el ambiente como ayuda a } \\
\text { conservar la biodiversidad }\end{array}$ & & 0 \\
\hline & $\begin{array}{l}\text { AA5. Aporte a la conservación } \\
\text { del área protegida }\end{array}$ & $\begin{array}{l}\text { Buenas prácticas de manejo en áreas } \\
\text { protegidas de acuerdo a la } \\
\text { planificación establecida en el área }\end{array}$ & 1 & \\
\hline & $\begin{array}{l}\text { AA6. Manejo de desechos } \\
\text { sólidos }\end{array}$ & $\begin{array}{l}\text { Indica medidas para reducir la } \\
\text { cantidad de desechos sólidos } \\
\text { producidos por las actividades } \\
\text { turísticas de la empresa. }\end{array}$ & 1 & \\
\hline & $\begin{array}{l}\text { AA 7. Manejo de aguas } \\
\text { residuales }\end{array}$ & $\begin{array}{l}\text { Determinar lineamientos para un } \\
\text { adecuado manejo de las descargas de } \\
\text { tanques sépticos y baterías sanitarias }\end{array}$ & & 0 \\
\hline & $\begin{array}{c}\text { AA8. Utilización de materiales } \\
\text { alternativos }\end{array}$ & $\begin{array}{l}\text { Productos y servicios priorizando la } \\
\text { utilización de materias primas } \\
\text { fácilmente degradables que } \\
\text { minimicen el impacto ambiental. }\end{array}$ & 1 & \\
\hline & AA9. Transporte de insumos & $\begin{array}{l}\text { Establece acciones para minimizar } \\
\text { los impactos ambientales producidos } \\
\text { por la transportación de insumos y } \\
\text { productos }\end{array}$ & 1 & \\
\hline & $\begin{array}{l}\text { AA10. Proveedores orgánicos } \\
\text { comunitarios }\end{array}$ & $\begin{array}{l}\text { Enfoca a la empresa hacia la } \\
\text { búsqueda de proveedores de } \\
\text { producción orgánica y de comercio } \\
\text { justo preferentemente de las } \\
\text { comunidades locales } \\
\end{array}$ & 1 & \\
\hline & AA11. Cumplimiento de la ley & $\begin{array}{l}\text { Orienta el cumplimiento de las leyes } \\
\text { de carácter ambiental y turístico }\end{array}$ & 1 & \\
\hline & $\begin{array}{l}\text { AA12. Promueve la educación } \\
\text { ambiental }\end{array}$ & $\begin{array}{l}\text { Incentiva a la empresa a integrar a la } \\
\text { educación ambiental como parte de } \\
\text { la oferta turística }\end{array}$ & & 0 \\
\hline & Subtotal 3 Ámbito Ambiental & & 8 & 0 \\
\hline & $\begin{array}{c}\text { Evaluación Total (Subtotal } \\
1+2+3 \text { ) }\end{array}$ & & 12 & 18 \\
\hline & Porcentaje de cumplimiento \% & & $40 \%$ & $60 \%$ \\
\hline & Total de indicadores evaluados & & 30 & \\
\hline
\end{tabular}

Realizado por: Myrian Isabel Piray Quezada

De acuerdo a los resultados de la matriz, se concluye que de los 30 indicadores analizados y evaluados se cumple con 12 que corresponde al $40 \%$ y no se cumplen con 18 indicadores que representan el $60 \%$. 


\section{Evaluación del Modelo de Gestión 2013}

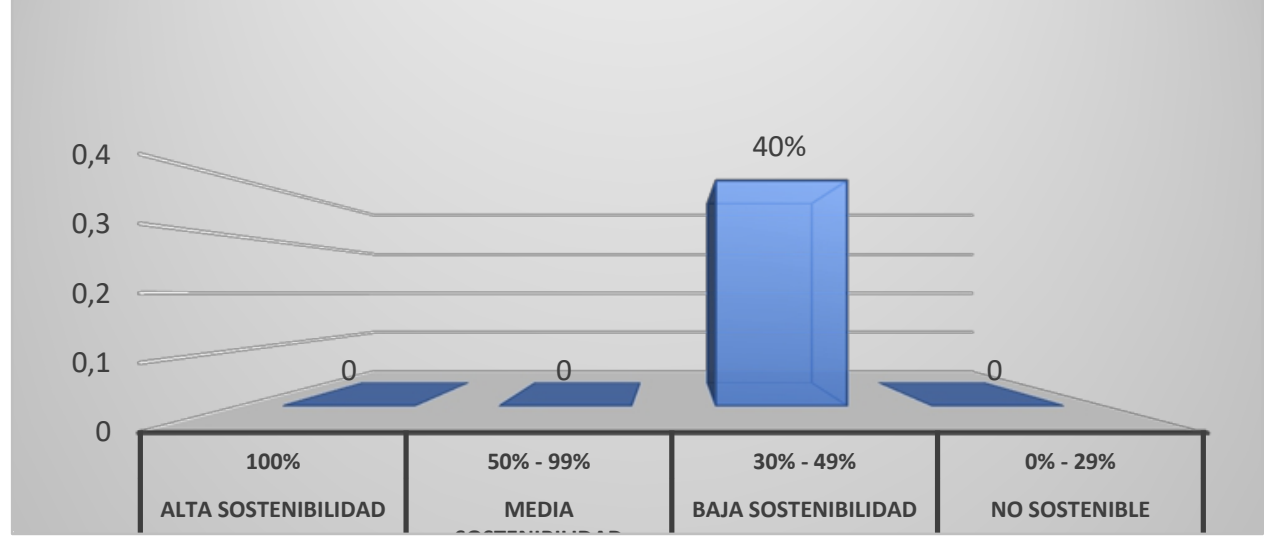

Figura 2. Nivel de cumplimiento de indicadores de sostenibilidad en el Modelo Realizado por: Myrian Isabel Piray Quezada

La figura 2. Evidencia que el resultado de cumplimiento de un $40 \%$ de los indicadores, está en el nivel Baja Sostenibilidad es decir, el modelo de gestión planteado está dentro del rango de cumplimiento del 30\% al 49\% de los indicadores de sostenibilidad (social, económico y ambiental).

\section{$>\quad$ Propuesta para mejorar el modelo de gestión existente de los refugios carrel $y$ whymper}

La nueva propuesta de Modelo de Gestión tiene por objetivo ajustar a los Refugios de alta montaña Carrel y Whymper al modelo de empresas ecoeficientes basada en la aplicación de Buenas Prácticas para el Turismo Sostenible, con enfoque en los Criterios Globales de Turismo Sostenible y el de Responsabilidad Social Corporativa o Responsabilidad Social Empresarial (RSE), lo que permitirá que la empresa actué bajo un modelo de negocio idóneo para la conservación y el desarrollo sostenible.

El Modelo de Gestión propuesto contribuirá al cumplimiento de los objetivos y políticas de eficiencia en la gestión de los servicios del área protegida, que permitirán mejorar la administración de los refugios, siendo compatible con los objetivos de conservación del área, asegurando no solo una rentabilidad económica de la inversión privada sino una sostenibilidad ambiental y social en la Reserva, con un modelo administrativo y operativo que satisfaga las más altas exigencias del turista que visita el área protegida. Y además sean compatible con el mercado interno de la empresa es decir sus empleados.

La propuesta establece indicadores en los tres ámbitos de la sostenibilidad: El económico, buscando rentabilidad y aprovechamiento al máximo de los recursos para beneficio de la empresa (Refugios). El ámbito social busca el bienestar de los involucrados en el ambiente tanto interno 
como externo de la empresa, establece políticas, gestión de calidad, análisis de entorno y motivación al personal que labora en la empresa a través de sueldos justos y cumplimiento de beneficios de ley, entre otros. Y el ambiental busca mantener el equilibrio con la naturaleza, siendo respetuosos de sus recursos y aprovechar al máximo su belleza, buscando dejar la menor huella ecológica en el área, acompañada de programas de remediación ambiental con el fin de devolver a la naturaleza parte de lo que ella entrega.

En resumen se proporcionará una nueva matriz al modelo que sintetice la nueva propuesta y monitoree el avance permanente del mismo. Está se presenta en el cuadro 5.

Cuadro 5. Matriz de indicadores del modelo propuesto

\begin{tabular}{|c|c|c|}
\hline \multicolumn{3}{|c|}{ ÁMBITO SOCIAL } \\
\hline INDICADORES & & \\
\hline $\begin{array}{l}\text { AMBIENTE } \\
\text { INTERNO }\end{array}$ & Objetivo & Contenidos y/o recursos \\
\hline $\begin{array}{l}\text { Gestión de } \\
\text { Sostenibilidad }\end{array}$ & $\begin{array}{l}\text {-Contar con directrices claras en el } \\
\text { ámbito social, económico y } \\
\text { ambiental, enlazadas con la } \\
\text { planificación y gestión estratégica } \\
\text { del área y la empresa. }\end{array}$ & $\begin{array}{l}\text { - Plan Estratégico Empresarial y del área } \\
\text { - Manual de procesos y procedimientos } \\
\text { operativos } \\
\text {-Sistema financiero que permita analizar } \\
\text { el flujo del dinero en la empresa } \\
\text { - Plan de manejo de residuos sólidos } \\
\text { - Plan de contingencia para casos de } \\
\text { emergencia. } \\
\text { - Disponer de seguros de garantía para } \\
\text { personas, bienes y vehículos que } \\
\text { permanezcan en las instalaciones del } \\
\text { servicio. } \\
\text { - Registro de visitantes para el servicio de } \\
\text { hospedaje y responsables de grupos } \\
\text { (guías u operadores turísticos) } \\
\text { - Libro de sugerencias para evaluación } \\
\text { del servicio. }\end{array}$ \\
\hline $\begin{array}{l}\text { Política de } \\
\text { Sostenibilidad }\end{array}$ & $\begin{array}{l}\text {-Establecer las políticas de } \\
\text { sostenibilidad de los refugios }\end{array}$ & $\begin{array}{c}\text { Misión } \\
\text { Visión } \\
\text { Análisis de la problemática actual } \\
\text { (FODA) } \\
\text { Política de Servicio } \\
\text { Política ambiental } \\
\text { Política social } \\
\text { Política Gestión Humana } \\
\text { Política Seguridad } \\
\end{array}$ \\
\hline $\begin{array}{l}\text { Gestión de la } \\
\text { Calidad }\end{array}$ & $\begin{array}{c}\text {-Incluir en la gestión, planificación y } \\
\text { organización sistemas integrados de } \\
\text { calidad }\end{array}$ & $\begin{array}{c}\text { Propiciar el desarrollo de factores de } \\
\text { Calidad: } \\
\text {-Empresarios con experiencia } \\
\text {-Equipo de trabajo con experiencia y } \\
\text { capacitación continua } \\
\text {-Amplia oferta de productos } \\
\text {-Amplias redes de comercialización } \\
\text { nacional e internacional } \\
\text {-Alta biodiversidad y contenido de } \\
\text { atributos } \\
\end{array}$ \\
\hline Monitoreo y & -Monitorear mensualmente el & Gestión de Talento Humano \\
\hline
\end{tabular}




\begin{tabular}{|c|c|c|}
\hline $\begin{array}{l}\text { acciones } \\
\text { correctivas. }\end{array}$ & $\begin{array}{l}\text { desarrollo de las actividades en los } \\
\text { refugios, junto a una evaluación y a } \\
\text { un plan de acción para corregir } \\
\text { posible problemas detectados }\end{array}$ & $\begin{array}{l}\text { Plan de monitoreo } \\
\text { Plan de acción }\end{array}$ \\
\hline $\begin{array}{l}\text { Salud y } \\
\text { seguridad en el } \\
\text { trabajo }\end{array}$ & $\begin{array}{l}\text {-Contar con un seguro de salud y de } \\
\text { riesgos laborales para el personal de } \\
\text { la empresa }\end{array}$ & $\begin{array}{c}\text { Afiliación al seguro social } \\
\text { Plan de riesgos } \\
\text { Botiquín de primeros auxilios } \\
\text { Capacitación al personal en primeros } \\
\text { auxilios }\end{array}$ \\
\hline $\begin{array}{c}\text { Formación del } \\
\text { personal de la } \\
\text { empresa }\end{array}$ & $\begin{array}{l}\text {-Capacitar al personal en busca de } \\
\text { potencializar sus habilidades en cada } \\
\text { puesto de trabajo }\end{array}$ & $\begin{array}{l}\text { Diagnóstico previo } \\
\text { Plan anual de capacitaciones }\end{array}$ \\
\hline $\begin{array}{l}\text { Grado de } \\
\text { satisfacción en el } \\
\text { trabajo de los } \\
\text { empleados } \\
\end{array}$ & $\begin{array}{l}\text {-Mejorar el rendimiento de los } \\
\text { empleados y lograr una identidad } \\
\text { con los objetivos de la empresa }\end{array}$ & $\begin{array}{c}\text { Reuniones periódicas } \\
\text { Encuesta de evaluación } \\
\text { Políticas laboral de la empresa }\end{array}$ \\
\hline $\begin{array}{l}\text { Permanencia de } \\
\text { los empleados en } \\
\text { la empresa }\end{array}$ & $\begin{array}{c}\text {-Motivar a los empleados y } \\
\text { asegurarles una estabilidad laboral en } \\
\text { la empresa con contratos fijos y } \\
\text { beneficios de ley }\end{array}$ & $\begin{array}{l}\text { Manual de Puestos y funciones } \\
\text { Organigrama estructural }\end{array}$ \\
\hline \multicolumn{3}{|c|}{ AMBIENTE EXTERNO } \\
\hline $\begin{array}{l}\text { Contribución al } \\
\text { desarrollo local } \\
\text { de la comunidad }\end{array}$ & $\begin{array}{l}\text {-Incorporar a los miembros de las } \\
\text { comunidades cercanas, previo a un } \\
\text { adiestramiento no menor a dos años, } \\
\text { para asegurar un nivel de } \\
\text { conocimiento mínimo para cumplir } \\
\text { los parámetros de calidad } \\
\text { establecidos para los refugios. } \\
\text {-Integrar a la comunidad en la lista } \\
\text { de proveedores de productos para los } \\
\text { servicios de los refugios. }\end{array}$ & $\begin{array}{c}\text { Plan de adiestramiento } \\
\text { Inventario de bodega } \\
\text { Lista de adquisiciones } \\
\text { Reportará con facturas, notas de venta y } \\
\text { liquidación de gastos de los proveedores }\end{array}$ \\
\hline $\begin{array}{l}\text { Aporte al rescate, } \\
\text { respeto y } \\
\text { protección de las } \\
\text { culturas y } \\
\text { poblaciones } \\
\text { locales }\end{array}$ & $\begin{array}{l}\text {-Conservar su identidad cultural a } \\
\text { través de su vestimenta, sus } \\
\text { tradiciones, sus artesanías y otros } \\
\text { elementos en la relación de servicio- } \\
\text { cliente en los refugios. } \\
\text {-Apoyar la organización de eventos } \\
\text { culturales en los refugios } \\
\end{array}$ & $\begin{array}{l}\text { Planes de revitalización cultural } \\
\text { Programación de eventos culturales }\end{array}$ \\
\hline $\begin{array}{l}\text { Nivel de } \\
\text { satisfacción de } \\
\text { los visitantes }\end{array}$ & $\begin{array}{l}\text {-Diversificar el producto por perfil } \\
\text { de visitantes } \\
\text {-Monitorear del nivel de satisfacción } \\
\text { del visitantes de diferentes épocas, y } \\
\text { en especial en feriados }\end{array}$ & $\begin{array}{c}\text { Encuestas } \\
\text { Productos turísticos } \\
\text { Plan de mejoras con los empleados }\end{array}$ \\
\hline \multicolumn{3}{|l|}{$\begin{array}{c}\text { ÁMBITO } \\
\text { ECONÓMICO }\end{array}$} \\
\hline $\begin{array}{l}\text { Productividad de } \\
\text { la empresa }\end{array}$ & $\begin{array}{c}\text {-Brindar una variedad de productos } \\
\text { de alimentación articulados a otros } \\
\text { servicios como hospedaje, alquiler } \\
\text { de equipos, información turista, y } \\
\text { venta de souvenir y educación } \\
\text { ambiental }\end{array}$ & $\begin{array}{c}\text { Artesanías } \\
\text { Menú variados } \\
\text { Folletería } \\
\text { Equipos de alta montaña } \\
\text { Guías locales }\end{array}$ \\
\hline $\begin{array}{l}\text { Rentabilidad de } \\
\text { la empresa }\end{array}$ & $\begin{array}{l}\text {-Monitorear permanentemente el } \\
\text { flujo de caja de la empresa con el fin }\end{array}$ & $\begin{array}{c}\text { Flujo de Ingresos- Egresos } \\
\text { TIR }\end{array}$ \\
\hline
\end{tabular}




\begin{tabular}{|c|c|c|}
\hline & $\begin{array}{c}\text { de asegurar la máxima rentabilidad } \\
\text { para la misma }\end{array}$ & $\begin{array}{c}\text { VAM } \\
\text { Análisis- costo Beneficio } \\
\text { TRC } \\
\text { PE }\end{array}$ \\
\hline $\begin{array}{l}\text { Salarios y } \\
\text { beneficios }\end{array}$ & $\begin{array}{l}\text {-Contar con salarios justos para el } \\
\text { personal que motiven su buen } \\
\text { desempeño }\end{array}$ & $\begin{array}{l}\text { Tabla de Remuneraciones Mínimas } \\
\text { Sectoriales actualizada. } \\
\text { Bonificaciones de desempeño }\end{array}$ \\
\hline $\begin{array}{l}\text { Inversiones en } \\
\text { investigación, } \\
\text { desarrollo e } \\
\text { innovación } \\
\end{array}$ & $\begin{array}{c}\text {-Fomentar la investigación, el } \\
\text { desarrollo de la innovación a través } \\
\text { del Programa de Manejo de la } \\
\text { Biodiversidad } \\
\end{array}$ & $\begin{array}{l}\text { Proyectos y programas } \\
\text { Investigadores }\end{array}$ \\
\hline $\begin{array}{l}\text { Impuestos o } \\
\text { contribución total } \\
\text { a las arcas de la } \\
\text { administración } \\
\text { pública }\end{array}$ & $\begin{array}{c}\text {-Evidenciar la legalidad de la } \\
\text { empresa ante diferentes instituciones } \\
\text { y contribuir a las arcas del estado de } \\
\text { acuerdo a los parámetros de ley } \\
\text { establecidos }\end{array}$ & $\begin{array}{c}\text { Permisos: } \\
\text { Mintur } \\
\text { Gads } \\
\text { Ministerio de Salud } \\
\text { Cuerpo de Bomberos } \\
\text { SRI y otros } \\
\end{array}$ \\
\hline $\begin{array}{l}\text { Cumplimiento de } \\
\text { compromisos } \\
\text { económicos con } \\
\text { proveedores }\end{array}$ & $\begin{array}{l}\text {-Realizar contratos anuales de } \\
\text { adquisición de productos para los } \\
\text { restaurantes con las comunidades de } \\
\text { la zona. }\end{array}$ & $\begin{array}{c}\text { Lista de precios con políticas de precios } \\
\text { justo } \\
\text { Contratos anuales } \\
\text { Listado de productos } \\
\text { Lista de proveedores } \\
\text { Cronograma de entrega y pagos } \\
\end{array}$ \\
\hline $\begin{array}{l}\text { Gestión de } \\
\text { mercadeo }\end{array}$ & $\begin{array}{c}\text {-La gestión de mercadeo permitirá } \\
\text { conocer el mercado y saber } \\
\text { direccionar bien las estrategias de } \\
\text { marketing. }\end{array}$ & $\begin{array}{c}\text { Estudio de mercado (oferta- demanda- } \\
\text { demanda insatisfecha) } \\
\text { Demanda (nacional e internacional } \\
\text { últimos } 4 \text { años) } \\
\text { Oferta (atractivos naturales, culturales) }\end{array}$ \\
\hline \multicolumn{3}{|c|}{ ÁMBITO AMBIENTAL } \\
\hline $\begin{array}{l}\text { Gestión del } \\
\text { recurso agua }\end{array}$ & $\begin{array}{l}\text {-Mantener y controlar el uso del agua } \\
\text { a través de registro periódico, que } \\
\text { detecten a tiempo fugas y/o } \\
\text { desperdicios el recurso. } \\
\text {-Incentivar el ahorro del agua entre } \\
\text { sus visitantes. } \\
\text {-Reutilizar el agua para regadío }\end{array}$ & $\begin{array}{c}\text { Filtros de caudal } \\
\text { Registros de control } \\
\text { Personal técnico } \\
\text { Carteles de concientización } \\
\text { Mantenimiento de tuberías }\end{array}$ \\
\hline $\begin{array}{l}\text { Uso de } \\
\text { tecnología de } \\
\text { energía } \\
\text { renovable }\end{array}$ & $\begin{array}{c}\text { - Aprovechar al máximo la energía } \\
\text { solar, uso de paneles energéticos. } \\
\text { - Utilizar equipos con ahorro de } \\
\text { energía. } \\
\text { - Analizar la factibilidad de energía } \\
\text { alternativa como la eólica. }\end{array}$ & $\begin{array}{c}\text { Focos, lámparas, cocinas y equipos para } \\
\text { ahorrar energía }\end{array}$ \\
\hline $\begin{array}{l}\text { Minimizar el } \\
\text { calentamiento } \\
\text { global }\end{array}$ & $\begin{array}{c}\text {-Generar conciencia ambiental entre } \\
\text { los pobladores para erradicar } \\
\text { costumbres que afectan al } \\
\text { ecosistema. } \\
\text {-Generar Proyectos de recuperación } \\
\text { de áreas deterioradas en la reserva } \\
\end{array}$ & $\begin{array}{l}\text { Capacitación a habitantes de la zona } \\
\text { Proyectos de remediación ambiental } \\
\text { Participación de escuelas y colegios en } \\
\text { procesos de reforestación con especies } \\
\text { nativas }\end{array}$ \\
\hline $\begin{array}{l}\text { Aporte a la } \\
\text { conservación de } \\
\text { la Biodiversidad }\end{array}$ & $\begin{array}{c}\text {-Asignar presupuesto para la } \\
\text { conservación a través de programas } \\
\text { de fauna y flora del lugar. } \\
\text {-Generar programas de rescate de } \\
\text { recursos arqueológicos. }\end{array}$ & $\begin{array}{l}\text { Programa de conservación Flora, fauna y } \\
\text { recursos culturales y arqueológicos }\end{array}$ \\
\hline $\begin{array}{c}\text { Aporte a la } \\
\text { conservación del }\end{array}$ & $\begin{array}{l}\text {-Apoyar el cumplimiento de los } \\
\text { programas de conservación plateados }\end{array}$ & $\begin{array}{l}\text { Programas Control y Vigilancia, Uso } \\
\text { Público y Turismo, Manejo de la }\end{array}$ \\
\hline
\end{tabular}




\begin{tabular}{|c|c|c|}
\hline área protegida & $\begin{array}{c}\text { para el área y convertirse en } \\
\text { supervisores del cuidado ambiental }\end{array}$ & $\begin{array}{l}\text { Biodiversidad (Sub programa: } \\
\text { Investigación y Monitoreo), } \\
\text { Comunicación, Educación y } \\
\text { Participación Ambiental, y } \\
\text { Administración y Planificación } \\
\end{array}$ \\
\hline $\begin{array}{l}\text { Manejo de } \\
\text { residuos sólidos }\end{array}$ & $\begin{array}{c}\text {-Manejo de residuos en los refugios a } \\
\text { través de los tres R. } \\
\text {-Crear Brigadas de limpieza } \\
\text { voluntaria en coordinación con el } \\
\text { MAE }\end{array}$ & $\begin{array}{c}\text { Brigadas } \\
\text { Basureros ecológicos } \\
\text { Camas de lombricultura y compost }\end{array}$ \\
\hline $\begin{array}{l}\text { Manejo de aguas } \\
\text { residuales }\end{array}$ & $\begin{array}{l}\text {-Reducir los residuos a través del uso } \\
\text { apropiado del agua en cocina y baños } \\
\text {-Controlar y mantener los pozos } \\
\text { sépticos. } \\
\end{array}$ & $\begin{array}{c}\text { Tubería especializada } \\
\text { Productos para el control y } \\
\text { mantenimiento de pozos sépticos }\end{array}$ \\
\hline $\begin{array}{l}\text { Utilización de } \\
\text { materiales } \\
\text { alternativos }\end{array}$ & $\begin{array}{l}\text {-Mantener las condiciones técnicas } \\
\text { de remodelación de los refugios, } \\
\text { tales como aislamiento térmico, uso } \\
\text { de maderas provenientes de } \\
\text { plantaciones forestales, tratamiento } \\
\text { de aguas negras y desechos sólidos, } \\
\text { uso de energías limpias y mitigación } \\
\text { de impactos visuales. Mismos que } \\
\text { deberán ser mantenidos e } \\
\text { implementados en nuevos servicios a } \\
\text { futuro. }\end{array}$ & $\begin{array}{c}\text { Paneles solares } \\
\text { Material para construcciones ecológicas o } \\
\text { amigables con el ambiente }\end{array}$ \\
\hline $\begin{array}{l}\text { Transporte de } \\
\text { insumos }\end{array}$ & $\begin{array}{l}\text {-Contar con vehículos apropiados } \\
\text { para la trasportación de productos } \\
\text { comestibles y con personal } \\
\text { capacitado en normas de velocidad } \\
\text { en el área } \\
\end{array}$ & $\begin{array}{l}\text { Vehículos } \\
\text { Permisos }\end{array}$ \\
\hline $\begin{array}{l}\text { Proveedores } \\
\text { orgánicos } \\
\text { comunitarios }\end{array}$ & $\begin{array}{l}\text {-Incentivar a las comunidades a } \\
\text { generar productos orgánicos y } \\
\text { obtener certificaciones orgánicas }\end{array}$ & $\begin{array}{c}\text { Contratos proveedores } \\
\text { Normas de calidad y certificación } \\
\text { ambiental }\end{array}$ \\
\hline $\begin{array}{l}\text { Cumplimiento de } \\
\text { la ley }\end{array}$ & $\begin{array}{l}\text {-Cumplir las normas generales y } \\
\text { específicas para las áreas protegidas }\end{array}$ & $\begin{array}{c}\text { Constitución de la República del Ecuador } \\
\text { Ley Forestal y de Conservación de Áreas } \\
\text { Naturales y Vida Silvestre } \\
\text { Ley de Modernización del Estado, } \\
\text { Privatizaciones y Prestación de Servicios } \\
\text { Públicos } \\
\text { Reglamento a la Ley de Modernización } \\
\text { del Estado, Privatizaciones y Prestación } \\
\text { de Servicios Públicos } \\
\text { Texto Unificado de Legislación } \\
\text { Ambiental Secundaria } \\
\text { Reglamento Especial de Turismo en } \\
\text { Áreas Naturales Protegidas }\end{array}$ \\
\hline $\begin{array}{l}\text { Educación } \\
\text { ambiental }\end{array}$ & $\begin{array}{l}\text {-Realizar actividades de educación } \\
\text { ambiental con los visitantes. } \\
\text {-Coordinar con el MAE el desarrollo } \\
\text { de conciencia ambiental en escuelas } \\
\text { y colegios que visiten la reserva. } \\
\end{array}$ & $\begin{array}{l}\text { Lista de Instituciones } \\
\text { Folletos } \\
\text { Videos } \\
\text { Talento Humano }\end{array}$ \\
\hline
\end{tabular}




\section{Conclusion}

1. El buen funcionamiento de una empresa turística ubicada dentro de un área protegida, dependerá de la gestión administrativa de los responsables del área protegida, quienes son los llamados a establecer parámetros de funcionamiento que sean coherentes con los objetivos del área. El modelo de gestión elaborado en año 2013 no es aplicable a las condiciones actuales de la reserva, pues, a la presente fecha existen algunos cambios tanto en la infraestructura de los refugios como en las condiciones administrativas de los mismos.

2. La evaluación del modelo propone una línea base de los indicadores de sostenibilidad con los cuales se puede evidenciar el manejo desde un inicio hasta un fin de la gestión y administración de los refugios, los resultados de la evaluación del actual modelo (2013) evidenciaron una baja sostenibilidad del mismo, ya que solo cumple con el $40 \%$ de los indicadores evaluados en los tres ámbitos económico, social y ambiental.

3. El modelo de gestión propuesto surge de la necesidad de considerar parámetros internacionales de gran importancia en la actualidad que aterrizan en los ámbitos de la sostenibilidad en función de la realidad actual de la Reserva, construyendo una herramienta viable y de fácil manejo para los administradores de los refugios, quienes están muy familiarizados con las condiciones de la localidad, y además muestran un gran interés por armonizar la naturaleza y el turismo.

\section{References:}

1. Alianza GSTC, (2012). Criterios Globales de Turismo Sostenible para Destinos consultado el 10 de noviembre del 2016. Recuperado de: http://www.gstcouncil.org

2. Arias, Estefanía. (2013). Modelo de Gestión para la Operación de Servicios Turísticos en la Reserva de Producción de Fauna de Chimborazo (RPFCH), Refugios de Alta Montaña "Primos Carrel" y "Edward Whymper". Quito, Ecuador. pp.8.

3. Asamblea Constituyente, (2008). La Constitución Política del Ecuador. Derechos de la naturaleza. Artículo 71. Literal 1.

4. Ministerio del Ambiente del Ecuador. (2015). Plan de Manejo de Visitantes de la Reserva de Producción de Fauna Chimborazo. Riobamba- Ecuador. pp. 10.

5. Ministerio de Medio Ambiente, 2015. Pla Gerencial Operativo Anual. pp.2 Consultado el 20 de abril del 2015.

6. Ministerio de Medio Ambiente. (2016). Las Áreas Protegidas Apoyan el Cambio Hacia un Ecuador Verde, Documento elaborado en el marco del Proyecto de Sostenibilidad Financiera para el Sistema Nacional de Áreas Protegidas del Ministerio de Ambiente. pp.3. 
7. Ministerio de Medio Ambiente. (2007-2016). Políticas y Plan Estratégico del Sistema Nacional del Sistema Nacional. Global Environment Facility - Fondo para el Medio Ambiente Mundial (GEF-FMAM) . Banco Mundial. pp.20-25.

8. Ministerio de Medio Ambiente Perú. (2009). Guía de ecoeficiencia para empresas. Ministerio de Medios Ambiente del Perú (MINAM). pp.9.

9. Ministerio de Medio Ambiente (2015). Plan de Manejo del Visitante de la Reserva de Producción de Fauna Chimborazo. Riobamba Ecuador. pp.4.

10. Piray, Myrian. (2016). "Evaluación del Modelo de Gestión para la Operación de Servicios Turísticos en la Reserva de Producción de Fauna Chimborazo (rpfch), caso refugios carrel y whymper". ESPOCH- Riobamba. pp.29, 66.

11. Rainforest, Alliance. (2009). Guía para una Gestión Empresarial Sostenible. Agencia de los Estados Unidos para el Desarrollo Internacional (USAID) Fondo Multilateral de Inversiones FOMINBanco Interamericano de Desarrollo BID. pp.11-13.

12. Rainforest, Alliance. (2008). Guía de Buenas Prácticas para Turismo Sostenible. Agencia de los Estados Unidos para el Desarrollo Internacional (USAID). Defra. MINTUR. Embajada Británica México. pp.13.

13. SEMPLADES, (2013-2017). Proyecto Delimitación Física y Desarrollo de Turismo Sostenible en el Patrimonio de Áreas Naturales del Estado. Consultado el 13 de noviembre del 2016. Recuperado de: http://www.ambiente.gob.ec/wpcontent/uploads/downloads/2015/07/PANE.pdf. pp.3.

14. World Business Council for Sustainable Development (1996) Revisado el 14 de noviembre del 2016.(WBCSD). http://www.wbcsd.org/ pp. 1 